\title{
Research on Influencing Factors of Rural Children's Psychological Development in China
}

\author{
Ying Huang \\ School of Politics and Administration \\ Wuhan University of Technology \\ Wuhan, P. R. China \\ 1521761629@qq.com
}

\author{
Yanping $\mathrm{Yu}$ \\ School of Politics and Administration \\ Wuhan University of Technology \\ Wuhan, P. R. China \\ yanpingyu@whut.edu.cn
}

\begin{abstract}
There is little systematic research on the psychological development of rural children as a whole in previous studies. This study was designed to examine rural children's psychological development and its influencing factors. Responses from 2,410 rural children throughout the Central China were collected through a survey research. Factor analysis was used to analyze the variables of psychological development for rural children. Results indicate: (a) rural children are developing well in psychology, (b) the order of the important factors influencing rural children's psychological development are gregariousness, parental reliance and subjective well-being, (c) peer group is an important variable of subjective well-being of rural children. Based on the research conclusions, the paper proposes that families, schools, the society and the government should make joint efforts to raise the gregariousness awareness of rural children, to resolve the problems of rural children whose parents are migrant workers, and to guarantee rural children's mental health.
\end{abstract}

Keywords-rural children, psychological development, influencing factors, China

\section{INTRODUCTION}

Children are an important force in the future development of our nation. Judging from the United Nations' Convention on the Rights of the Child and China's Outline of Chinese Child Development (2011 - 2020), safeguarding the rights of children and promoting children's development are seen as a task of great significance. The $21^{\text {st }}$ Century Education Research Institute conducted an investigation on the current situation of school-age children in poverty-stricken areas of 20 provinces in China in 2014, and found that the mental health problem of school-age children in primary schools of towns is the most prominent. Rural children are restricted by many factors, such as regional economy and living environment. They should be paid more attention in psychological development than ordinary children. This paper seeks to answer the following questions: What is the psychological development status of children in rural areas? What factors affect their psychological development? How to help rural children promote their psychological development?

\section{LITERATURE REVIEW}

The academic circles have carried on many discussion and researches on rural children's psychological development. From the point of research object, Sun and other researchers

Fund support: Project sponsored by National College Students' Innovation and Entrepreneurship Training Program in 2017 (Project number: 20171049719005) randomly selected 1,704 rural juveniles and conducted an investigation in 2015. They found that left-behind children's psychological performance is worse than that of non-left-behind children [1]. Shao conducted a questionnaire among 90 left-behind children in 2016 drew a conclusion that the left-behind children have certain psychological problems [2]. Wang and other researchers conducted a literature review concerning the self-concept of left-behind children in 2015[3]. Zhang compared left-behind children with non-left-behind children by using mental health diagnosis and test as well as individual interviews in 2012[4]. It can be seen that scholars mostly take left-behind children as the research subject when studying the issues of Children in Chinese rural areas. This will not only ignore the psychological needs of non-left-behind children, but also bring labels and stigma to the left-behind children.

From the selection of variables influencing the psychological development, Jia and Tian used sense of loneliness as the variable to measure the psychological problems of left-behind children in 2010[5]. Wu and other researchers studied the left-behind children's resilience and depression in 2015 [6]. Zhang researched on the mental health status of left-behind children from the perspectives of isolation, lack of love, selfishness, rebellious attitude and weak rational consciousness in 2016 [7]. Therefore, there is no unified variable for the measurement of rural children's psychological problems in China, and most of them are negative or neutral ones, and there are few positive and subjective variables.

In summary, there is little systematic research on the psychological development of rural children as a whole in the academic circle, and most of them are negative or neutral variables. Therefore, this paper focuses on the study of rural children's psychological status, and draws conclusions based on factor analysis, and puts forward corresponding suggestions in order to promote the development of rural children's mental health.

\section{RESEARCH Methods}

In this study, a quantitative method was used to complete the survey from January 2016 to July 2016, and the data were collected and analyzed by STATA13.0.

In order to ensure the representativeness of the samples, and improve the measurement reliability and validity, this investigation adopts random sampling method in the central 
region of China - Zhushan County, Shiyan City, Hubei province. Thirty seven primary and secondary schools in 17 towns were randomly selected, and 2,500 questionnaires were handed to rural children aged between 7 and 15. Finally 2,410 copies were returned, accounting for $96.4 \%$ of all copies.

Twenty nine variables related to rural children's psychological development were selected and analyzed. And the 149 samples with missing values were excluded, so there are 2,261 effective samples for data analysis in the paper. Factor analysis was used to analyze the psychological development variables of rural children. Based on the study of the internal dependence among the variables, the multiple measured variables are transformed into a few irrelevant aggregative indicators (i.e. factors), and the dimensionality reduction is achieved by simplifying the data.

\section{RESEARCH RESULTS}

\section{A. Data Test of KMO Value}

The data were carefully tested and analyzed. The partial correlation between variables and the KMO test value is 0.7946 , greater than 0.70 . In statistical analysis, KMO value is greater than 0.7 , indicating that factor analysis can be done. Therefore, this set of data is suitable for factor analysis.

\section{B. Factor Analysis}

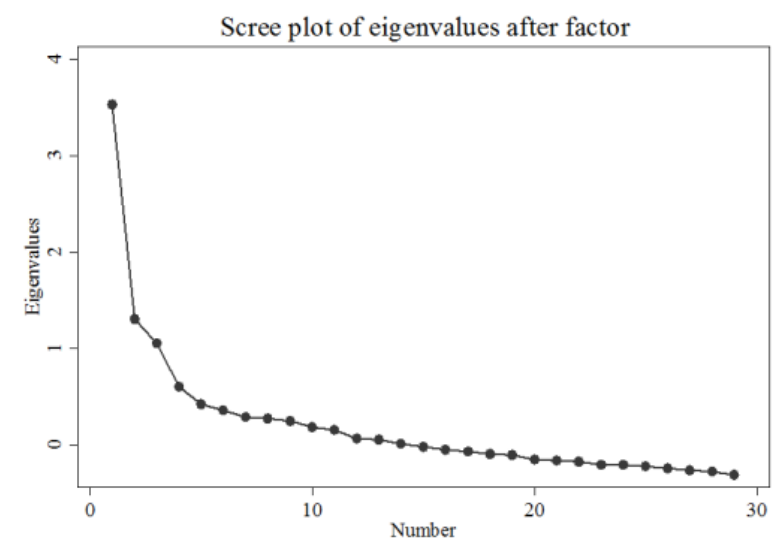

Fig. 1. Scree Plot of Psychological Status of Rural Children

Through the observation of the scree plot (Fig.1), it was found that the data after the third factor showed a relatively gentle trend, so it was decided to select the 3 factors.

TABLE I. EIGENVALUE, VARIANCE CONTRIBUTION RATE AND CUMULATIVE VARIANCE CONTRIBUTION RATE OF COMMON FACTORS

\begin{tabular}{cccc}
\hline $\begin{array}{c}\text { Common } \\
\text { Factor }\end{array}$ & Eigenvalue & $\begin{array}{c}\text { Variance } \\
\text { Contribution } \\
\text { Rate \% }\end{array}$ & $\begin{array}{c}\text { Cumulative } \\
\text { Variance } \\
\text { Contribution } \\
\text { rate \% }\end{array}$ \\
\hline Factor1 & 2.93243 & 47.73 & 47.73 \\
Factor2 & 1.51182 & 24.61 & 72.33 \\
Factor3 & 1.45403 & 23.66 & 96.00 \\
\hline
\end{tabular}

The calculation results of common factor eigenvalues shows that there are three factors whose eigenvalue is bigger than 1 , therefore the three factors are retained. The explainable cumulative variance contribution rate is $96.00 \%$, the unexplained information of variable is $4.00 \%$, and the population variance's variable information explanation ability is relatively good. According to table I, it can be found that rural children's psychological problems is reflected more prominently in the first common factor, with the variance contribution rate as $47.73 \%$. The other two factors in descending order is F2 (24.61\%) and F3 (23.66\%) according to the contribution rate.

In order to highlight the differences among the factors, the maximum variance method is used to rotate and the factor load matrix is obtained. It is found that the absolute values of correlation coefficient between the principal factors and partial variables are relatively small and these variables are not representative. In order to better measure the psychological development of rural children and make the research more scientific and standardized, it is determined to exclude the variables whose load values are less than 0.4. Through screening, there are five variables whose load values are greater than 0.4 in the first common factor, namely v11 (0.4326), v15 (0.5623), v16 (0.4272), v18 (0.5961) and v24 (0.5389). There are three variables whose load values are greater than 0.4 in the second common factor, namely v22 (0.5114), v25 (0.5729) and v27 (-0.5067). there are three variables whose load values are greater than 0.4 in the third common factor, namely v3 (0.4176), v4 (0.4031) and v5 $(-0.4011)$.

In order to understand the correlation between the common factors and the rural children's psychological development, the scores of the three variables are calculated, and the average score of the factors is calculated (Table II ).

TABLE II. SCORES OF FACTORS

\begin{tabular}{|c|c|c|c|}
\hline \multirow{2}{*}{ Variable } & \multicolumn{3}{|c|}{ Factor } \\
\hline & F1 & F2 & F3 \\
\hline $\begin{array}{l}\text { Feel happy together with } \\
\text { classmates v3 }\end{array}$ & & & 0.18482 \\
\hline $\begin{array}{l}\text { Feel happy together with friends } \\
\text { v4 }\end{array}$ & & & 0.18341 \\
\hline Feel happy alone, v5 & & & -0.17159 \\
\hline $\begin{array}{l}\text { The society has given us a lot of } \\
\text { help, and I'm going to repay them } \\
\text { positively. v11 }\end{array}$ & 0.11968 & & \\
\hline $\begin{array}{l}\text { Your satisfaction with your } \\
\text { current life v15 }\end{array}$ & 0.16666 & & \\
\hline $\begin{array}{l}\text { Do you like to get along with } \\
\text { others? v16 }\end{array}$ & 0.09127 & & \\
\hline $\begin{array}{l}\text { Do you think people around you } \\
\text { care about you? v18 }\end{array}$ & 0.18880 & & \\
\hline $\begin{array}{l}\text { Do you miss your mom and } \\
\text { dad ?v22 }\end{array}$ & & 0.23999 & \\
\hline $\begin{array}{l}\text { Your attitude towards parents } \\
\text { going out for work v24 }\end{array}$ & 0.17864 & & \\
\hline $\begin{array}{l}\text { Absence of parents due to work } \\
\text { makes you feel lonely v25 } \\
\text { Nobody takes care of you }\end{array}$ & & 0.28071 & \\
\hline $\begin{array}{c}\text { because your parents have left } \\
\text { you for work. v27 }\end{array}$ & & -0.24071 & \\
\hline Average & 0.14901 & 0.09333 & 0.06555 \\
\hline
\end{tabular}

\section{Analysis on Results of Factors}

A total of three factors (including 11 variables) are extracted by exploratory factor analysis. The three factors that influence the psychological development of rural children include gregariousness, parental reliance and subjective 
well-being, and the the principal factors decreases successively in importance, with details as below:

The variables of Factor One are respectively v11, v15, v16, v18 and v24. The definition of "gregariousness" is that the relationship between the members is harmonious and the individual is willing to get along with his or her peers. The keywords of the five variables of Factor One are "giving back to the society", "satisfaction about life", "getting along with others" and " attitude towards surrounding people", which are similar to "relationship with the mass", "community”, "getting along with peers” and "getting involved in others' activities” in the definition of "gregariousness". The author holds the idea that these five variables reflect the rural children's psychological performance, and that the five variables of the factor have relatively high load values. Therefore, the factor is named as "gregariousness".

The variables of Factor Two are v22, v25 and v27 respectively. Variable 22 can reflect the attachment degree of rural children to their parents. variable 25 reflects that rural children are very dependent on their parents. while variable 27 shows that some rural children do not rely too much on their parents. Based on the comprehensive characteristics of these three variables, the author deems that these three variables reflect the rural children's reliance on their parents, and that the relationship between the three variables and Factor Two is high. Therefore, Factor Two is named as "parental reliance".

The three variables of Factor Three are: v3, v4 and v5. In 2016, Feng argued that subjective well-being is the subject's overall assessment of the status of their lives according to the standards set by themselves, including life satisfaction (cognitive evaluation) and emotional experience (positive and negative emotion) [8]. The three variables of Factor Three all reflect the features of happiness, and they are consistent with "positive emotion", a component of "subjective well-being". Meanwhile, the three variables have relatively high load values. Therefore, Factor Three is named as "subjective well-being".

\section{DISCUSSION}

Through the further dimension reduction analysis, this paper finds that the three factors that influence the psychological development of rural children are gregariousness, parental reliance and subjective well-being. The specific details are as follows:

\section{A. Gregariousness}

The scores of the five variables of Factor One are respectively 0.11968 points (v11), 0.16666 points (v15), 0.09127 points (v16), 0.18880 points (v18) and 0.17864 points (v24), and their average level is 0.14901 points. Among them, v18 is most correlated to Factor One. The factor analysis shows that gregariousness is the most important factor affecting the psychological development of rural children, and they are generally in a state of being gregarious.

The rural children surveyed in the paper are in an important period of developing self-identity. They need to improve the level of self-consciousness under correct guidance and answer the question "who am I" in order to avoid the chaos of identity[9]. Gregariousness is an important part of the development of rural children's self-identity.

The efforts can be made in the following two aspects to strengthen rural children's gregariousness: First, parents should choose the right way of parenting. Too much spoiling will make rural children lose communication ability while the free-range parenting style will let rural children be unable to perceive love and integrate into the community. parents should cultivate rural children's ability to communicate with others and perceive others' love by their personal examples and verbal instruction, encourage them to participate in group activities and support them to play a role in the group. Second, schools should make full use of the resources. Schools are the places where children congregate and where rural children easily get acquainted with their peers. The schools should carry out all kinds of group activiteis on learning, life and games so as to let rural children find their role and value in cooperation and competition. and they should also hire professional psychological teachers to offer group work for rural children, in a bid to consciously cultivate and enhance their gregariousness and self-identity, thus promoting the physical and mental health of rural children.

\section{B. Parental Reliance}

The scores of the three variables of Factor Two are respectivly 0.23999 points (v22), 0.28071 points (v25), and -0.24071 (v27), and their average level is 0.09333 points. Among them, v25 is most correlated with Factor Two. The factor analysis shows that rural children are generally reliant on their parents.

Duan argued in 2017 that the absence of parents has adverse effect on children's long-term development[10]. From the feedback of rural children in this research, children will miss their parents and feel lonely rather than feel free when their parents leave their homtown for work.

The efforts in the following aspects can be made to give play to the role of parental reliance in psychological development of rural children: First, rural children's parents should pay attention to children's emotional needs and often communicate with their children. At the same time, children should learn to actively contact their parents and express their needs. Second, the schools can organize colorful extracurricular activities to enrich the after-school life of rural children and relieve their negative emotions caused by the absence of parents. Thirdly, rural teachers should pay attention to children's emotional change and actively chat with them to understand their needs. And they should also strengthen contact with the children's parents so as to jointly help children ease their negative emotion. Fourthly, rural children should learn to actively participate in peer group activities and make friends in the activities, in order to get peer support and help. Fifthly, the government should, in the means of policies, guide and attract migrant workers to return to their hometown to seek employment so as to address the problem of rural children's lack of parentage at its source.

\section{Subjective Well-Being}

The scores of the three variables of Factor Three arerespectively 0.18482 points (v3), 0.18341 points (v4)and 
-0.17159 points (v5), and their average level is 0.06555 points. Among them, v3 is most correlated with Factor Three. The results show that rural children have a positive manifestation in subjective well-being.

Subjective well-being is an important psychological parameter reflecting the quality of individual life in a society. The rural areas are mostly underdeveloped with lack of resources and no ability to provide a relatively superior learning and living environment for rural children. Therefore, rural children face more negative events in life than ordinary children. In this context, how rural children evaluate life satisfaction and how they react to mood and emotion determines whether they can have a physically and mentally healthy growth. Therefore, subjective well-being is one of the important factors to promote rural children's psychological development and improve their quality of life.

The efforts can be made in the following aspects to improve the subjective well-being of rural children: First, parents and teachers should actively communicate with rural children to understand their confusion, and then offer effective guidance and help so as to improve rural children's life satisfaction. Second, schools should carry out psychological quality education and work with parents to jointly help rural children improve their psychological quality. Thirdly, parents and teachers should pay attention to children's behavior guidance and training, so that rural children can be aware of their own strengths and expertise, and teach children the skills of communication to reduce conflict with others. Fourthly, rural children should spontaneously develop the habit of engaging with others, actively take part in peer group activities and make friends with those sharing their interests. In this process, they can gain recognition in the community and explore their own value so as to obtain subjective well-being.

\section{SUMMARY}

To sum up, gregariousness, parental reliance and subjective well-being are important factors affecting the psychological development of rural children, and rural children's psychological status tends to be developing well. The psychological development of children in rural areas cannot be maintained and promoted relying on a single strength in a short period of time. Instead, it calls for joint efforts by the society, government, schools, parents, peer groups and the rural children themselves so as to raise rural children's awareness of gregariousness and tackle the problem of absence of parentage.

\section{REFERENCES}

[1] X. Sun, Y. Tian, Y. Zhang, et al. Psychological Development and Educational Problems of Left-Behind Children in Rural China [J]. School Psychology International, 2015, 36(3):227-252.

[2] Q. F. Shao and C. J. Deng. Prevention Strategy for Psychological Problems of Left-Behind Children in Rural Primary and Middle Schools from the Perspective of School Education [J]. Economic Research Guide, 2016 (21): 37-38. (In Chinese)

[3] X. Wang, L. Ling, H. Su, et al. Self-concept of left-behind children in China: a systematic review of the literature [J]. Child Care Health \& Development, 2015, 41(3):346-355.

[4] Y. N. Zhang. Study on the Difference of Mental Health between Left-behind Children and Non-Left-behind Children -- A Case Study of Southern Shaanxi [J]. Theory Research, 2012 (2): 43-44. (In Chinese)

[5] Z. Jia and W. Tian. Loneliness of left-behind children: a cross-sectional survey in a sample of rural China [J]. Child Care Health \& Development, 2010, 36(6):812-817.

[6] Y. L. Wu, X. Zhao, X. X. Ding, et al. A prospective study of psychological resilience and depression among left-behind children in China [J]. Journal of Health Psychology, 2015.

[7] J. S. Zhang. Psychological Problems and Countermeasures of Left-behind Children [J]. Chinese Journal of Child Health, 2016, 24 (9): 897-899. (In Chinese)

[8] X. Z. Feng, L. Zhang and H. H. Shao. Relationship between Resilience and Subjective Well-being in Left-behind Children in Junior High School [J]. Chinese Journal of Child Health, 2016, 24 (6): 573-575. (In Chinese)

[9] Eysenck, M. W., and Keane, M. T., Cognitive Psychology: A Student's Handbook, 6th Edition, Psychology Press, 2010.

[10] C. R. Duan, M. H. Lai, M. Qin. Research on the Change Trend of Left-behind Rural Children in China since 21st Century [J]. China Youth Study, 2017 (6): 52-60. (In Chinese) 